\title{
Making your genes come true
}

\section{Winning in biotechnology depends on managing risk through work, superb planning, and cross-disciplinary efforts at innovation.}

\section{Eric Tomlinson}

Building a biotechnology company is in many ways comparable to creating a well-functioning, purpose-built racing machine. Plans must be crafted, components assembled, and then special fuel in the form of innovation blended to propel it on its path. Both the way the machine handles in the race, and the rate at which it travels, will depend on the driver's ability to take and manage risks.

Building a racing machine that wins is never an individual effort. It requires a team that has learned to work effectively together through shared purpose and trust. Bioentrepreneurs are most often attracted to participating on this team by the opportunity to either design or drive such a machine-or both. As biotechnology companies prepare to enter their fourth decade on the "Formula One" Grand Prix Circuit, there are certain principles of both building and driving a biotechnology-based racing machine that can prepare an emerging bioentrepreneurs's dream machine for victory.

\section{Never fear the blank sheet of paper}

Lord Byron wrote there is nothing more difficult than the beginning. I disagree. It is easy to start-especially on the wrong foot. The beginning is the point of maximum leverage, when the passion and the energy are high, when every moment is shared. The challenge at this crucial stage is to create the foundations for an enterprise that delivers sustained value to its shareholders, employees, and customers. The imperatives are generally to make the correct key appointments; to license technology that enables an appropriate economic return; to attract investors who can encourage others; to pick the right location; and perhaps, most importantly, to form a scientific and business team that can learn as it achieves.

Our own experiences illustrate this. When we founded GeneMedicine in 1992, gene therapy was being heralded as a "cure" for all genetic disorders. With this wide-spread acclaim as a background, we launched the company with the belief that the approaches for gene delivery-based primarily on viral or

Eric Tomlinson is president and CEO of GeneMedicine, Inc., 8301 New Trails Drive, The Woodlands, TX 77381-4248

(tomlie@genemedicine.com).

\section{The responsiveness of the organization to the needs of} its employees, customers, and shareholders affects the spirit of the enterprise.

cell-based methods-were not up to the challenge of delivering human therapeutics. What's more, the level of scholarship in gene delivery and gene construct design was still in its infancy-of minimal help to a therapeutics-based company.

Having already begun to assemble our company, we found it necessary to start anew. We would have to redesign how we were going to assemble the components that would enable us to win. Taking this route entailed considerable risk for everyone in the organization. But believing that we could be the world leader in turning genes into medicines and that the ability to do this would provide a new quality of patient care gave us no alternative but to launch an R\&D program dedicated to developing a synthetic route for gene therapy.

\section{Empower your team}

How were we able to motivate both research and management to believe that creating an entirely new design was a winning strategy? Primarily through ensuring that everyone agreed on the goal and that they had a personal stake in its achievement. This came both through equity participation upon hiring and attainment of high performance, and also through involvement of all personnel in each and every crucial corporate step.

This is an extraordinarily demanding process for everyone, requiring attention and understanding. The empowerment process in most emerging organizations does not begin immediately. The founding group are joined by many new colleagues who are perhaps unaware of the field or its issues. Their education can be folllowed by empowerment. It is of course something that occurs at a different rate for each employee, line manager, and team.

The responsiveness of the organization to the needs of its employees, customers, and shareholders affects the spirit of the enterprise. This comes from a vision created and shared by the people of the organization, which is developed through a set of values (which we toiled to produce). These values changed as we matured and became larger.

What had been an early outpouring of faith and belief needed very careful reconsideration and crafting when we became a multifunctional R\&D operation that was 10 times larger. The original simple points needed them to reflect an emerged culture, and we took the opportunity, through group discussion and iterative steps, to craft a set of beliefs and values that reflected our collective beliefs about "How we want to do things here."

The process of doing so alleviated some of the strains and stresses that had emerged in our fast-developing operation. An external moderator was helpful to the process. Among the first things visitors to our facility now see are the two pages of text that are our values and beliefs posted alongside fun pictures of each of us (and arranged near our patent trophies). These describe how people behave and why, what is admired and why, and what the big goals are and why.

Our desire was to be open and to share everything: data, discussions with corporate partners, board meeting outcomes and topics, successes and failures. Such transparency allowed us to see what parts were working well and what parts were not. This generally takes place at our weekly company meetings. As this knowledge spreads, people test out the information against their own experiences and respond positively or negatively (but always constructively-remember those values now!)

An enterprise must be prepared to challenge how it operates and be willing to think about itself and the industry in new ways. I relish that job candidate who asks why should gene therapy be of any use! Craft practices and approaches that meet your needs, not the needs of a consultant or an industry norm. Importantly, craft a board that is competent, excited, and has a vested interest in the success of the business.

\section{Plan the next step}

Once the prototype is assembled, it will need to be tested and tuned repeatedly to make it race ready. The speed with which you accomplish this will depend on how quickly you can compare your results to the desired goal and take decisive actions to put it on the right 
track. One tried and true technique is always to know in advance how to proceed based on the three inevitable outcomes: it worked, it failed, or the result was inconclusive, according to a predefined standard of performance. If a team cannot define the consequences of success or failure before beginning, then the work is probably not worth doing.

Scientists in our business generally recognize that while knowledge generation is fine, they are in the business of innovation-a completely different use of the information derived from basic science. Therefore, the team must accept failure quickly, learn from it, and then move on to ask the next question that will yield the goal.

\section{Only those with a broad bandwidth of experience will be able to lead bio- science teams to define, pursue, and maintain progress along the critical path.}

\section{Use cross-disciplinary platforms}

While the initial core of most biotechnology companies is a group of scientists trained in molecular and cell biology and genetics, as the company grows, as many as $80 \%$ of the people on the team will be trained in other scientific, clinical, and professional disciplines-each with its own language and approach. Because of the inherent complexity of such an organization, there is an ongoing need to constantly update it with information about how the latest bioscience issues are impacting product R\&D. This demands that cross-disciplinary platforms be developed for maintaining cutting-edge capabilities.

For example, a former colleague and I spent many hours teaching each other molecular cell biology and thermodynamic processes, respectively. One time he mentioned a "polarized cell." I assumed he meant a cell bearing a negative and a positive electrical charge, not realizing at first that such words describe the spatial orietation of a tissue-resident cell within the body.

While an easy error for a physical scientist, through this conversation I discovered the emerging science around defining the cytoskeleton and the incredible world of cell recognition and intracellular processing. Together, we set about to define those processes and to exploit them for drug and gene delivery purposes.

What remain challenging to the success of a multidisciplinary biotechnology organization are the different approaches used by sci- entists from diverse backgrounds. For example, some use only rigorous quantitative endpoints, while others use visual display; some take a reductionist approach, while their team colleagues may be investigating a hypothesis. It thus becomes apparent that only those with a broad bandwidth of experience will be able to lead bioscience teams to define, pursue and maintain progress along the critical path.

\section{Conclusions}

Building a biotechnology racing organization requires the ability to manage risk through teamwork, superb planning, and cross-disciplinary efforts at innovation. Having gone through this experience at GeneMedicine, we have acquired as part of this process the confidence to make our genes come true by developing a completely new approach to gene therapy. This has enabled us achieve our initial goal of designing products that are intended to be used as conventional drugs in regular medical practice. The race is not yet over. We will know we have won when we are able to provide patients with a new improved quality of pharmaceutical care.

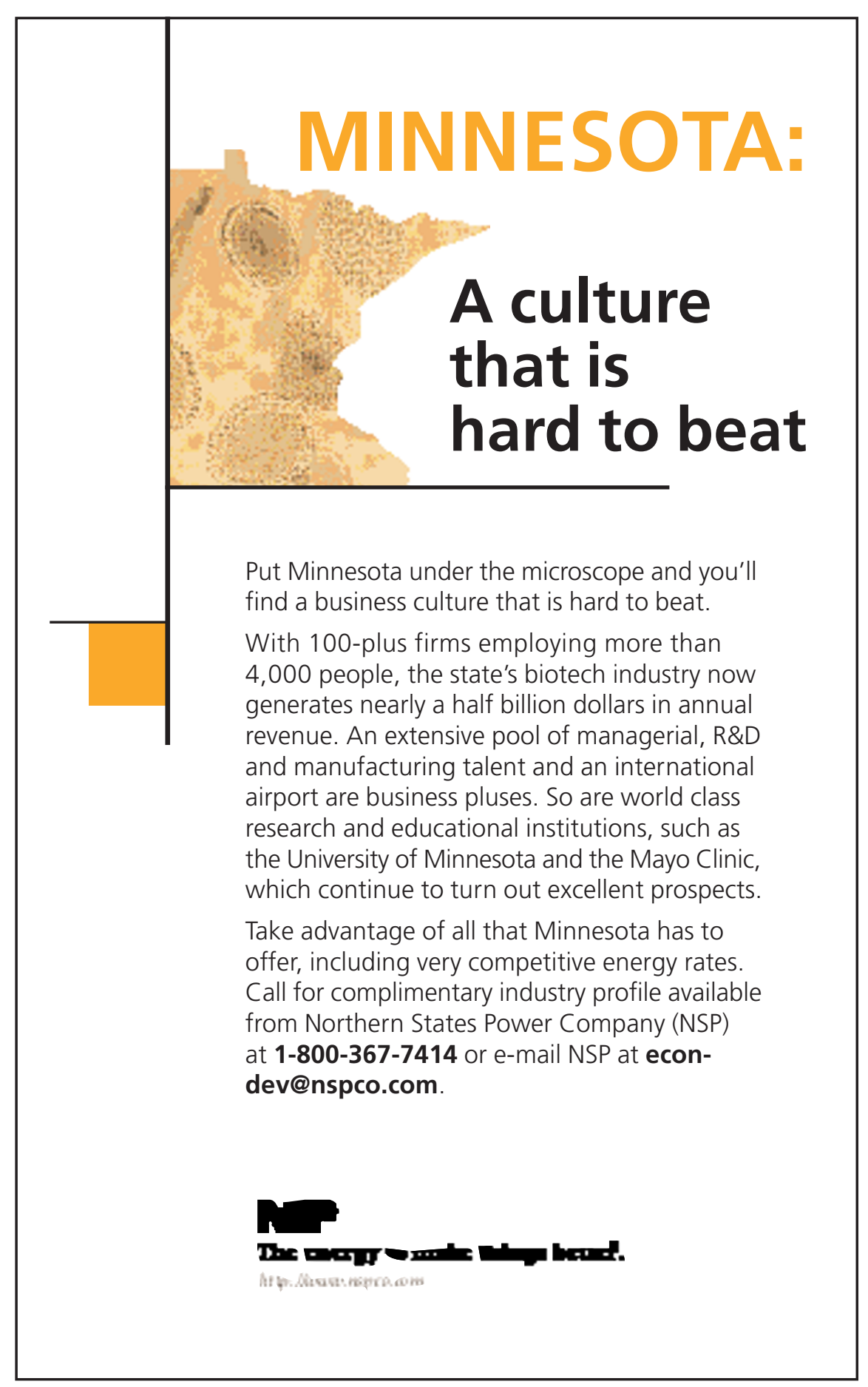

